Please send trade news information and illustrations to Arveen Bajaj at the BDJ, 64 Wimpole Street, London W1G 8YS. Trade news is supplied as a service to the reader and does not imply endorsement by the BDJ. Normal and prudent research should be exercised before purchase of use of any product mentioned.

\section{TRADE NEWS \\ WHAT'S NEW}

\section{Molecular testing}

Dentalyse is a new UK based molecular testing service offering identification of bacterial pathogens together with genetic polymorphism analysis as a diagnostic aid for the detection and confirmation of periodontitis. The micro-IDent test provides a detailed profile of the five most important periodontal pathogenic bacteria present and their relative quantities. The profile can be extended to a further six bacteria using the micro-IDent plus test, permitting the dentist to make an informed choice of antibiotic strategy.

During treatment, micro-IDent offers a means of monitoring the bacterial load to assist in determining the effectiveness of the chosen therapy. Subsequent tests can indicate if bacteria have been eliminated, or if re-colonisation has occurred, the company asserts. GenoType PST provides a genetic analysis of specific IL-1 polymorphisms which can affect the immune system increasing susceptibility to periodontal disease. Identification of patients carrying these polymorphisms permits the dentist to devise an appropriate treatment plan to restrict and prevent disease progression.

Specimen collection for both tests is performed at the dental surgery using the free of charge sampling kits provided by the Dentalyse service. Analysis is carried out in the Dentalyse laboratories in Merseyside, with results generated in the form of a comprehensive report, returned to the dentist within five days of receipt of the sample. For further information, or to request a free of charge sampling kit, contact www.dentalyse.com.

Reader response number 51

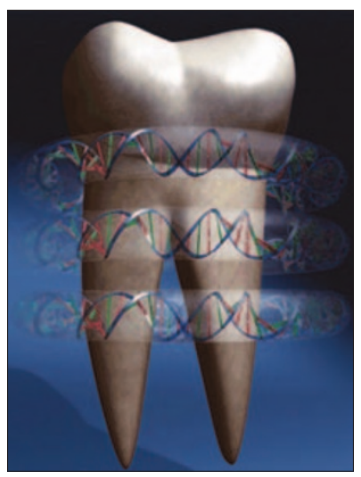

\title{
Incredible characters
}

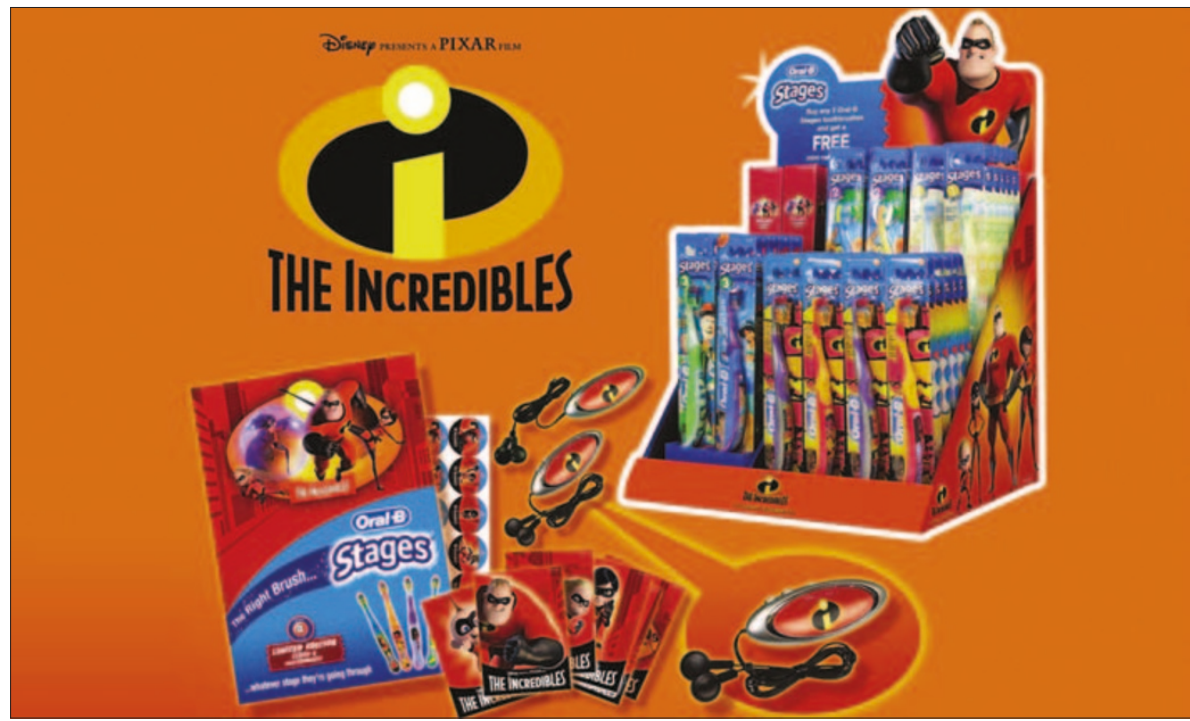

Oral-B have recently launched Stages 4 toothbrushes featuring 'The Incredibles' characters.

It is giving away a free 'The Incredibles' radio to patients purchasing any two of its Stages range of toothbrushes. 'The Incredibles' is the latest animated film release from the Disney/Pixar team. Practices will

\section{Touch screen technology}

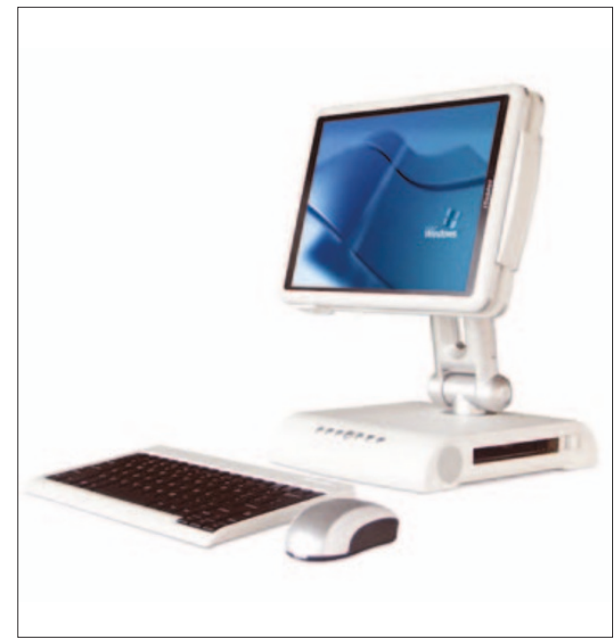

The new PaceBlade Slimbook from 2L is a fully portable touch-screen tablet PC with windows XP Pro.

It can be used when an initial consultation with the patient takes place and a number of treatment options open to the customer can be explored, the company claims.

The choice and detail of treatment materials are displayed and are selected by touching the appropriate box on the screen.

With wireless LAN technology, the Slimbook can be taken from treatment room to the dental reception area, can be wiped clean in case of spillage and needs no keyboard or mouse.

The product also has the ability to play DVDs during treatment as well as being used as a notebook to log treatment details and is available from Camtech Systems Ltd. For more information visit www.paceblade.com.

Reader response number 53 

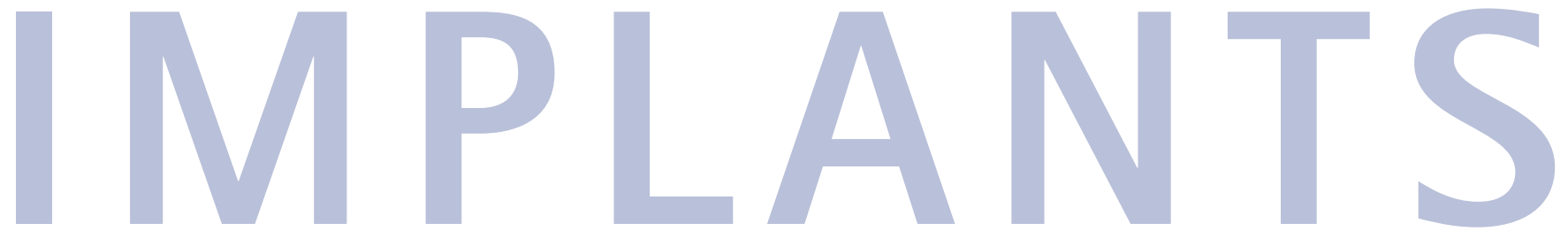

\section{New treatment}

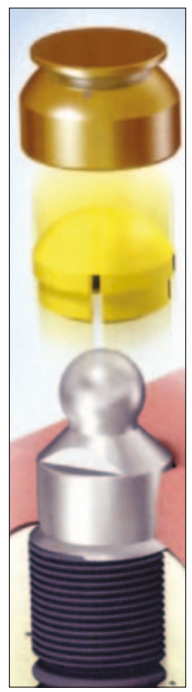

Clix, the new product for overdenture treatment from Astra Tech Dental Implants is easy to place and to change, according to the company.

It offers optimal retention for every patient and features a plastic insert for minimal wear to the abutments. The company also claims that overdenture attachments to dental implants provides patients with a sense of security and can minimise the time spent adjusting loose dentures.

Reader response number 54

\section{Chairside fitting}

Cerec is a blend of intuitive CAD/CAM hardware and software technology that enables a dentist to design, manufacture and fit biocompatible and metal-free ceramic restorations at the chairside in one visit, without the need for conventional impressions and temporisation.

The Cerec method enables the maximum preservation of tooth substance and with an adhesive space of 50 microns it provides a good fit, the company claims.

The product spans all types of restorations from crowns (including implants) to inlays, onlays and veneers and is available from Ceramic Systems.

\section{Reader response number 55}

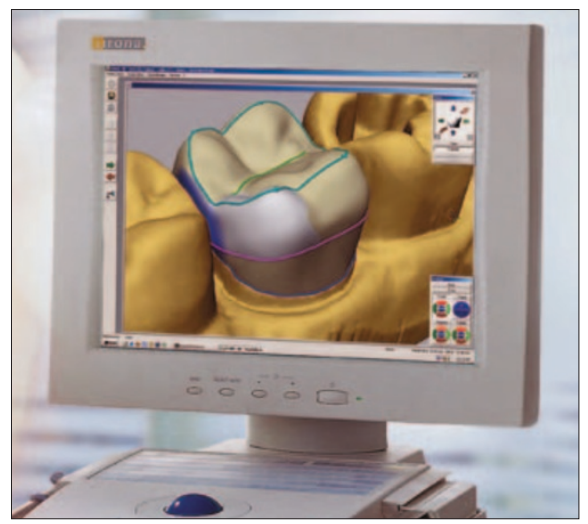

Higher strength

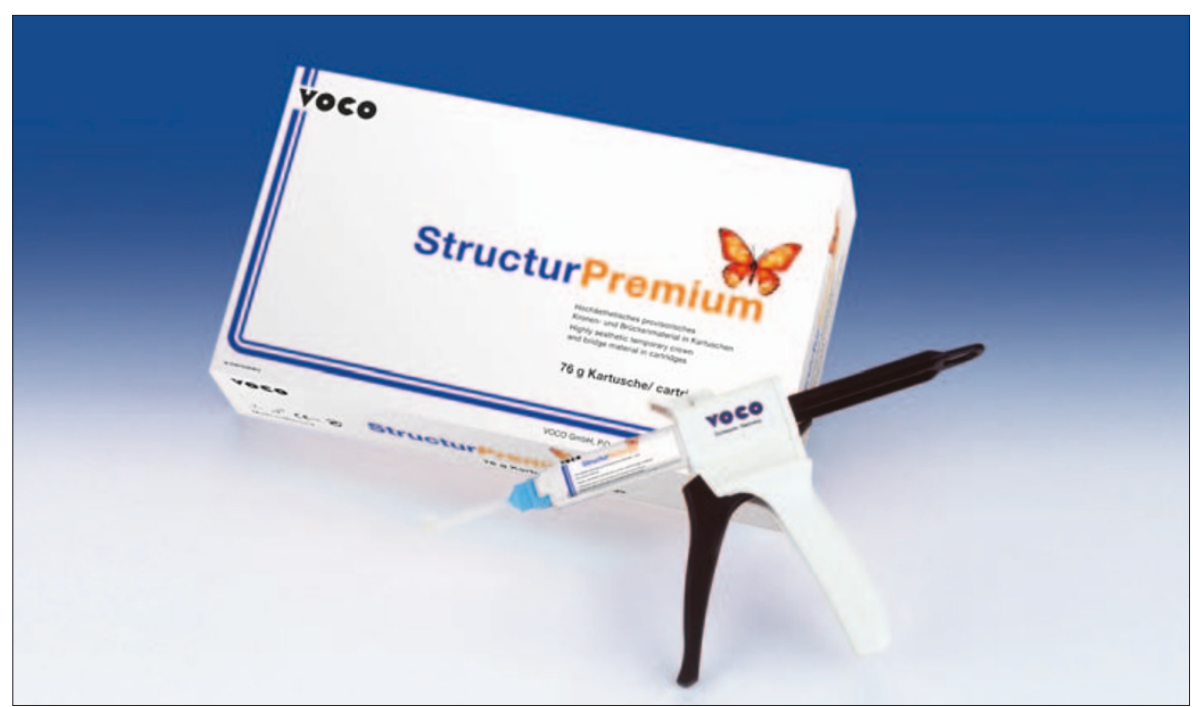

Voco introduces the first temporary crown and bridge material with the material properties of a microhybrid composite.

Structur Premium's new filler combinations provide even higher strength and brilliant gloss, the company claims, with more thorough curing and high translucency for better aesthetics. New initiators increase final hardness and prolong the elastic phase for more convenient application. With its triple optimised formula it reaches the material properties of microhybrid composites and shows a fracture resistance of over $1000 \mathrm{~N}$ on three-unit- bridges and a transverse strength of 140 MPa. Its high stability and fracture resistance minimizes the risk of repair or replacement of temporaries and allows fine trimming of the temporary to the gingival margin. Its low polymerization shrinkage optimises the precision of fit of the finished temporaries while low water uptake keeps Structur Premium shades stable long-term. Additionally, all five shades (A1, A2, A3, B3, BL) are fluorescent and offer increased brilliance of the temporaries under all light conditions.

Reader response number 56

\section{Diamond tipped}

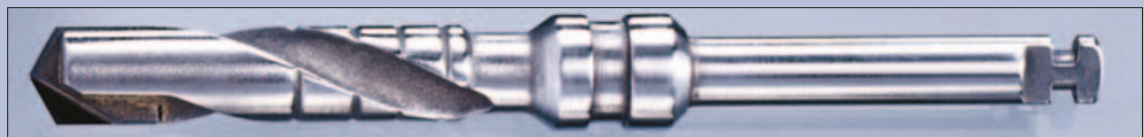

Diatip is an implant drill tipped with PCD (Poly Crystalline Diamond), the sharpest form of engineered diamond crystals.

It means less heat is generated making the operation cleaner and faster and ensures the point stays sharp and accurate, the company claims.

Since the diamond-tipped drills do not require additional pressure to penetrate bone, the spiral drill produces bone sliv- ers, which are easy to collect. As the tip of the drill stays sharp and the diameter doesn't change, the accuracy and ease of use of the product can dispense with the need for an intermediate drill. Three sizes are available; $2.8 \mathrm{~mm}$ (pilot), 3.25 and $3.75 \mathrm{~mm}$ to suit standard implants.

Diatip is available exclusively from The Dental Directory.

Reader response number 57 


\section{Natural gum shade system}

GC has developed a light cured composite for the highly aesthetic reproduction of missing gingival tissue. GC Gradia Gum is indicated for implant superstructures and for other fixed or removable prostheses.

It allows the dentist to reproduce unlimited natural gingival shades, as the layering technique combined with a variety of modifiers provides a number of possibilities. According to the company, the product shows good physical properties, natural appearance and easy handling.

Reader response number 58
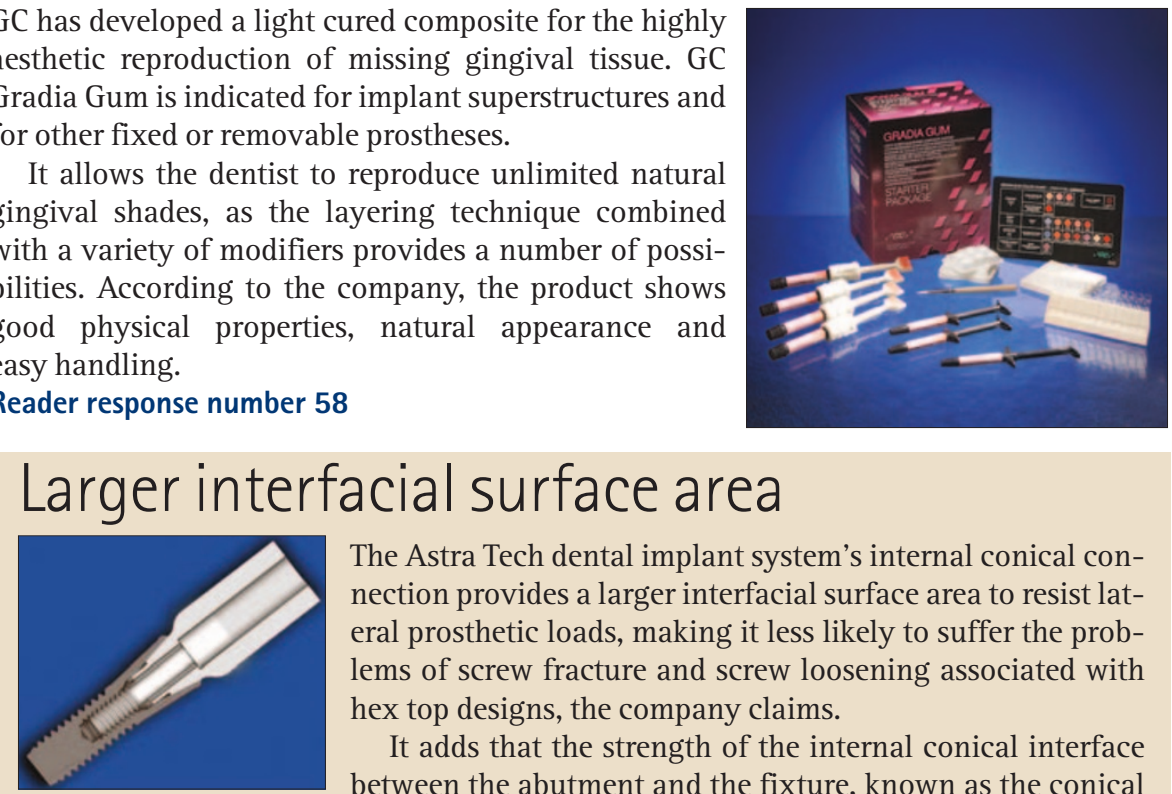

acial surface area seal design can ensure a firm, durable fit of the implant to the abutment, minimising the risk of micro-leakage and component loosening.

Reader response number 59

\section{Implant kit}

Molar's Implant Kit contains a comprehensive range of products, specifically for use by the implant patient. The kit includes a Special Care toothbrush, a TePe select extra soft toothbrush for general oral hygiene and the implant and interspace brush for specific cleaning around the implant abutment posts.

Sample packs of the TePe Interdental brushes and Proximal brush are included, as well as a toothbrush travel case which can be used for any of the TePe toothbrushes. Also included are plastic interdental sticks and Proxi-Floss. The implant kit is available exclusively from Molar for $£ 9.90$ each and there is a minimum order quantity of three packs.

Reader response number 60

\section{Faster bone growth}
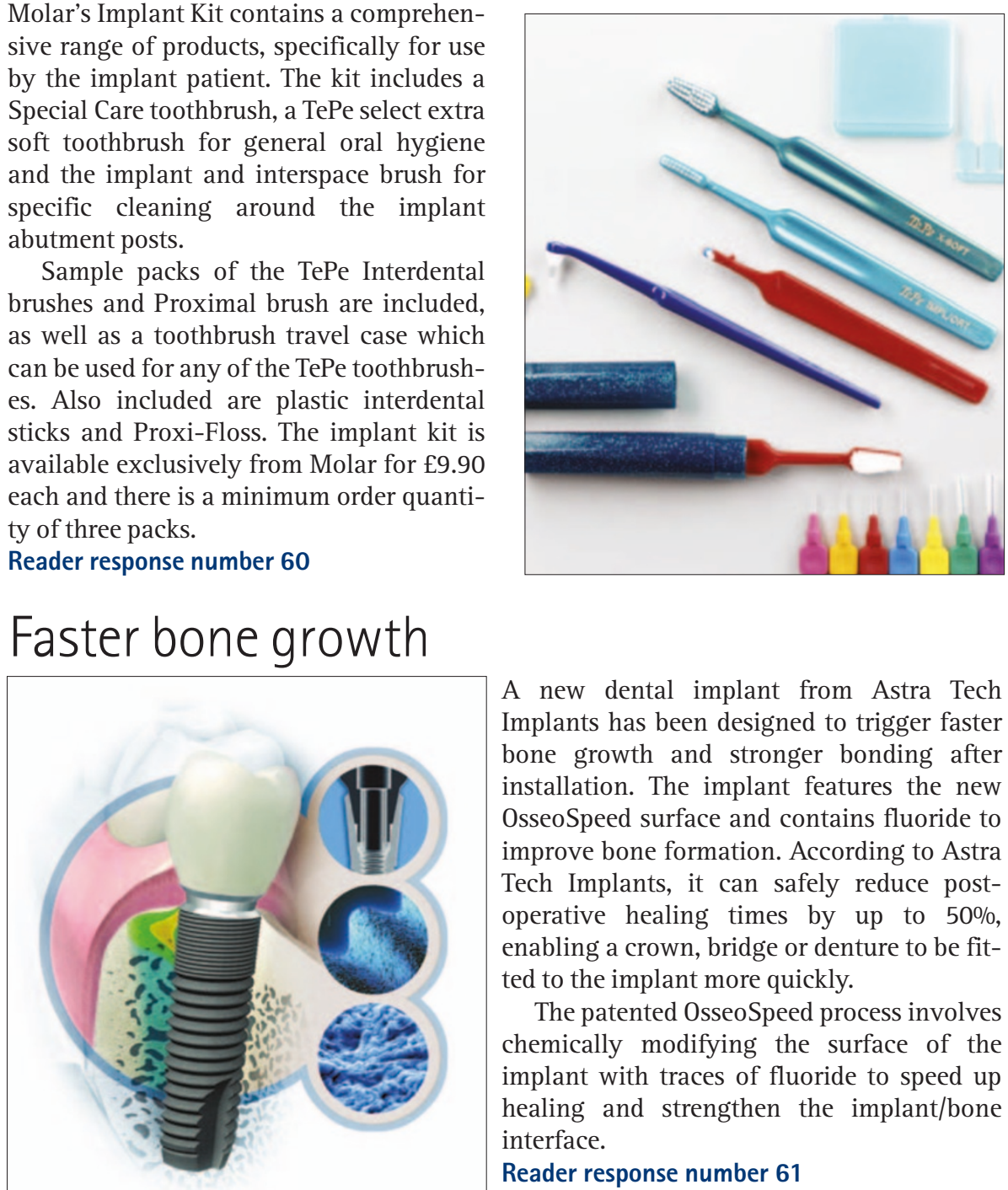

A new dental implant from Astra Tech Implants has been designed to trigger faster bone growth and stronger bonding after installation. The implant features the new OsseoSpeed surface and contains fluoride to improve bone formation. According to Astra Tech Implants, it can safely reduce postoperative healing times by up to 50\%, enabling a crown, bridge or denture to be fitted to the implant more quickly.

The patented OsseoSpeed process involves chemically modifying the surface of the implant with traces of fluoride to speed up healing and strengthen the implant/bone interface.

Reader response number 61 